\title{
A Gender Comparison of Bone Metabolic Changes After Gastric Cancer Surgery: A Prospective Observational Study
}

\author{
YOSUKE ATSUMI ${ }^{1}$, YASUSHI RINO ${ }^{1}$, TORU AOYAMA ${ }^{1}$, NAOKO OKUDA $^{1}$, \\ SHINNOSUKE KAWAHARA ${ }^{1}$, KEISUKE KAZAMA ${ }^{1}$, MASAKATSU NUMATA ${ }^{1}$, \\ HIROSHI TAMAGAWA ${ }^{1}$, TAKASHI OSHIMA ${ }^{2}$, NORIO YUKAWA ${ }^{1}$ and MUNETAKA MASUDA ${ }^{1}$ \\ ${ }^{1}$ Department of Surgery, Yokohama City University, Yokohama, Japan; \\ ${ }^{2}$ Department of Gastrointestinal Surgery, Kanagawa Cancer Center, Yokohama, Japan
}

\begin{abstract}
Background/Aim: This study was designed to investigate gender-related differences in changes in bone metabolism after gastric cancer surgery. Patients and Methods: We prospectively recruited 47 patients (38 males and 9 females) who had early gastric cancer. The bone mineral density (BMD), serum levels of 1,25-dihydroxy vitamin $D \quad\left(1,25(\mathrm{OH})_{2} \mathrm{VD}\right), 25$-hydroxy vitamin $D$ $(25(O H) V D)$, and estradiol (E2) were measured before and after surgery. Results: BMD significantly decreased 12 months after surgery by median degrees of $3.4 \%$ and $3.9 \%$ in male and female patients, respectively $(p<0.001$ and $p=0.023)$. There was no significant difference between both genders in the rate of change in BMD after surgery. The serum E2 level in male patients significantly increased by a median value of $22 \mathrm{pg} / \mathrm{ml} 12$ months after gastrectomy $(p=0.030)$. Both the serum 25(OH)VD and $1,25(\mathrm{OH})_{2} \mathrm{VD}$ levels remained nearly within the normal range throughout the observation period in both male and female patients. Conclusion: BMD significantly decreased within 12 months after gastrectomy in both male and female patients with gastric cancer, and there was no significant gender-related difference in the rate of change in BMD.
\end{abstract}

Recently, the survival rate of gastric cancer patients has improved because of early diagnosis, curative surgery, and adjuvant chemotherapy $(1,2)$. Accordingly, bone disorders that occur after gastrectomy for gastric cancer have drawn attention as sequelae, along with dumping syndrome and

This article is freely accessible online.

Correspondence to: Yosuke Atsumi, Department of Surgery, Yokohama City University, 3-9, Fukuura, Kanazawa-ku, Yokohama, Japan. Tel: +81 457872645, Fax: +81 457860226, e-mail: yosuke31004@gmail.com

Key Words: Gastric cancer, bone, gastrectomy. anemia. Calcium and vitamin D deficiency caused by reduced food intake, reductions in gastric acid secretion, and inadequate mixing of biliary and pancreatic secretions due to rapid transit through the small intestine are considered to be causes of hyperparathyroidism followed by bone mineral loss and bone disorders (3-5). In particular, bone fractures impair patient's activities of daily living and quality of life. Furthermore, previous meta-analyses have reported a significant association between lower bone mineral density (BMD) and all-cause cardiovascular mortality $(6,7)$. A large retrospective study reported that fractures occurred on average 3.7 years postoperatively and the cumulative incidence of fractures increased up to a final of $40.6 \%$ (8).

However, the mechanisms of bone disorders after gastrectomy are not fully clear, and most previous studies investigating bone disorders after gastrectomy were retrospective or cross-sectional studies without BMD data before surgery (9-15). Hence, when BMD starts to decrease and the extent of the decline remain unclear. In addition, despite the fact that males and females have different bone metabolism due to differences in endocrinological factors, no study has estimated gender-related differences in the changes of BMD after gastric cancer surgery.

We previously recruited patients with early gastric cancer and reported prospective data on changes in male BMD before and after gastric cancer surgery (16). Female patients were also recruited at the same time. The purpose of the present study was to prospectively investigate gender-related differences changes in bone metabolism before and after gastrectomy in patients with gastric cancer.

\section{Patients and Methods}

Patients with advanced gastric cancer usually receive anticancer agents as adjuvant therapy after curative surgery $(2,17,18)$, and some studies demonstrated that anticancer agents could reduce BMD $(19,20)$. Therefore, we recruited only patients with early gastric cancer. A total of 52 consecutive patients underwent gastrectomy for early gastric cancer from April 2009 through March 2015 in our 
Table I. Clinicopathological features of 47 patients.

\begin{tabular}{lccc}
\hline Factor & Males & Females & $p$-Value \\
\hline $\mathrm{n}$ & 38 & 9 & \\
Age (years) & $68(35 \sim 84)$ & $63(60 \sim 78)$ & 0.43 \\
$\begin{array}{l}\text { BMI (kg/m2) } \\
\text { ECOG PS } \\
\quad \text { 0/1/2/3/4 }\end{array}$ & $23.4(17.3 \sim 29.0)$ & $21.4(18.6 \sim 27.1)$ & 0.69 \\
$\begin{array}{l}\text { Type of surgery } \\
\text { DG/TG/PG/ }\end{array}$ & $38 / 0 / 0 / 0 / 0$ & $9 / 0 / 0 / 0 / 0$ & \\
$\quad$ Partial resection & $23 / 11 / 3 / 1$ & $7 / 2 / 0 / 0$ & 0.88 \\
$\begin{array}{l}\text { Reconstruction } \\
\text { BI/RY/EG/None }\end{array}$ & $22 / 12 / 3 / 1$ & $7 / 2 / 0 / 0$ & 0.87 \\
$\begin{array}{l}\text { Depth of invasion } \\
\text { pT1a/pT1b }\end{array}$ & $16 / 22$ & $4 / 5$ & 1 \\
$\begin{array}{l}\text { Nodal involvement } \\
\text { pN0/pN1 }\end{array}$ & $36 / 2$ & $7 / 2$ & 0.16 \\
$\begin{array}{l}\text { Tumor recurrence } \\
\quad \text { Yes/no }\end{array}$ & $0 / 38$ & $0 / 9$ & \\
\hline
\end{tabular}

Continuous variables are shown as the median (range). BMI: Body mass index; ECOG-PS: Eastern Cooperative Oncology Group Performance Status; DG: distal gastrectomy; TG: total gastrectomy; PG: proximal gastrectomy; BI: Billroth-I reconstruction; RY: Roux-en-Y reconstruction; EG: esophagogastrostomy.

institution. We excluded patients with renal failure, liver failure, as well as patients receiving drug treatment with bisphosphonates or any other bone-active drugs, including vitamin $\mathrm{D}$, before surgery or during the follow-up period. After excluding patients who met the exclusion criteria, 48 patients were enrolled. Only one patient was not followed up for 2 years because he had metachronous esophageal cancer immediately after gastric cancer surgery and was thus excluded. Therefore, a total of 47 patients were finally evaluated.

This study was approved by the Institutional Review Board of Yokohama City University (Yokohama, Japan) and conducted according to the principles of the Declaration of Helsinki. Informed consent was obtained from all patients.

Bone densitometry. The BMD and T-score of the lumbar vertebrae (L2-L4) were measured by dual energy X-ray absorptiometry (DEXA) using a Hologic Discovery QDR system (Hologic Inc., Bedford, MA, USA). The T-score is the standard deviation from the mean BMD of young normal adults. A T-score between -1 and -2.5 indicates low bone mineral density (osteopenia), and a T-score below -2.5 is considered osteoporosis, as defined by the World Health Organization (WHO) (21). The National Osteoporosis Foundation (NOF) recommends that postmenopausal females and males aged 50 years or older who have low bone mineral density and certain risk factors and all patients with osteoporosis should consider receiving an osteoporosis treatment (22). The BMD and T-score were measured before and 1 and 2 years after surgery. The serum levels of 1,25-dihydroxy vitamin $\mathrm{D}\left[1,25(\mathrm{OH})_{2} \mathrm{VD}\right], 25$-hydroxy vitamin $\mathrm{D}[25(\mathrm{OH}) \mathrm{VD}]$, and estradiol (E2) were measured before surgery and every 3 months until 2 years after surgery. We also evaluated the clinicopathological and perioperative data of all patients.

We used the Wilcoxon signed-rank test to compare preoperative and postoperative continuous variables and the Mann-Whitney- $U$ test to compare continuous variables between female and male patients.
Table II. Bone mineral density and bone metabolism-related markers of 47 patients.

\begin{tabular}{|c|c|c|c|}
\hline \multirow[t]{2}{*}{ Factor } & \multicolumn{2}{|c|}{$\begin{array}{l}\text { Median (range) } \\
{[\text { Normal range] }}\end{array}$} & \multirow[b]{2}{*}{$p$-Value } \\
\hline & Males & Females & \\
\hline $\begin{array}{l}\text { Preoperative lumbar } \\
\text { spine BMD }\left(\mathrm{g} / \mathrm{cm}^{2}\right)\end{array}$ & $0.93(0.75 \sim 1.67)$ & $0.91(0.64 \sim 1.12)$ & 0.19 \\
\hline $\begin{array}{l}\text { Preoperative lumbar } \\
\text { spine T score }\end{array}$ & $-1.0(-2.5 \sim 5.3)$ & $-0.7(-3.1 \sim 0.9)$ & 0.52 \\
\hline $\begin{array}{l}\text { Preoperative serum } \\
1,25(\mathrm{OH})_{2} \mathrm{VD}(\mathrm{pg} / \mathrm{ml})\end{array}$ & $\begin{array}{l}58.8(31.9 \sim 93.1) \\
{[20.0 \sim 60.0]}\end{array}$ & $\begin{array}{l}58.4(24.4 \sim 83.3) \\
\quad[20.0 \sim 60.0]\end{array}$ & 0.57 \\
\hline $\begin{array}{l}\text { Preoperative serum } \\
25(\mathrm{OH}) \mathrm{VD}(\mathrm{ng} / \mathrm{ml})\end{array}$ & $\begin{array}{l}29(17 \sim 53) \\
{[10.0 \sim 55.0]}\end{array}$ & $\begin{array}{l}24(13 \sim 30) \\
{[10.0 \sim 55.0]}\end{array}$ & 0.071 \\
\hline $\begin{array}{l}\text { Preoperative serum } \\
\text { E2 }(\mathrm{pg} / \mathrm{ml})\end{array}$ & $\begin{array}{c}20.5(10 \sim 43) \\
{[20.0 \sim 60.0]}\end{array}$ & $\begin{array}{c}10(10 \sim 10) \\
{[\text { less than } 10]}\end{array}$ & $<0.001$ \\
\hline $\begin{array}{r}\text { Calorie intake at } \\
\text { discharge (kcal) }\end{array}$ & $1150(450 \sim 1900)$ & $1000(750 \sim 1250)$ & 0.22 \\
\hline
\end{tabular}

BMD: Bone mineral density; $1,25(\mathrm{OH})_{2} \mathrm{VD}: 1,25$ dihydroxyvitamin D; 25(OH)VD: 25 hydroxyvitamin D; E2: estradiol.

$p<0.05$ was considered to indicate statistical significance. All statistical analyses were performed with EZR (Saitama Medical Center, Jichi Medical University, Saitama, Japan), which is a graphic user interface for R (The R Foundation for Statistical Computing, Vienna, Austria). More precisely, it is a modified version of $\mathrm{R}$ commander designed to add statistical functions frequently used in biostatistics (23).

\section{Results}

Patient characteristics. Tables I and II give the patient characteristics according to each sex. We evaluated 38 male and 9 female patients. The median ages of the male and female patients were 68 years (range $=35-84$ years) and 63 years (range $=60-78$ years), respectively. The median body mass index (BMI) of male and female patients was 23.4 $\mathrm{kg} / \mathrm{m}^{2}\left(\right.$ range $\left.=17.3-29.0 \mathrm{~kg} / \mathrm{m}^{2}\right)$ and $21.4 \mathrm{~kg} / \mathrm{m}^{2}$ (range $=18.6-$ $27.1 \mathrm{~kg} / \mathrm{m}^{2}$ ), respectively. All patients had a good Eastern Cooperative Oncology Group Performance Status (ECOGPS), and tumor was confined to the mucosa or submucosa. Distal gastrectomy (DG), total gastrectomy (TG), proximal gastrectomy $(\mathrm{PG})$, and partial gastric resection were performed in 30 patients, 13 patients, 3 patients, and 1 patient, respectively. Billroth-I (BI), Roux-en-Y (RY), and esophagogastrostomy (EG) reconstruction were performed in 29 patients, 14 patients, and 3 patients, respectively. Only one patient underwent DG with RY reconstruction. There was no significant difference in the performed surgical procedures between the genders. All of the females were menopausal, and their serum E2 level was lower than 10.0 $\mathrm{pg} / \mathrm{ml}$. The preoperative serum E2 level was significantly 
A

Males

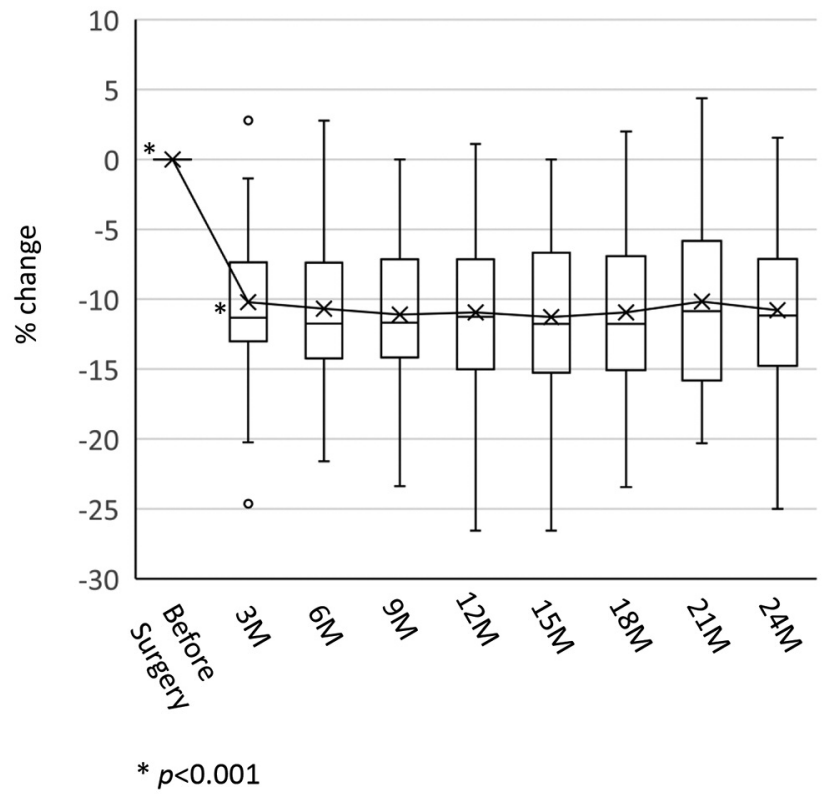

B Females

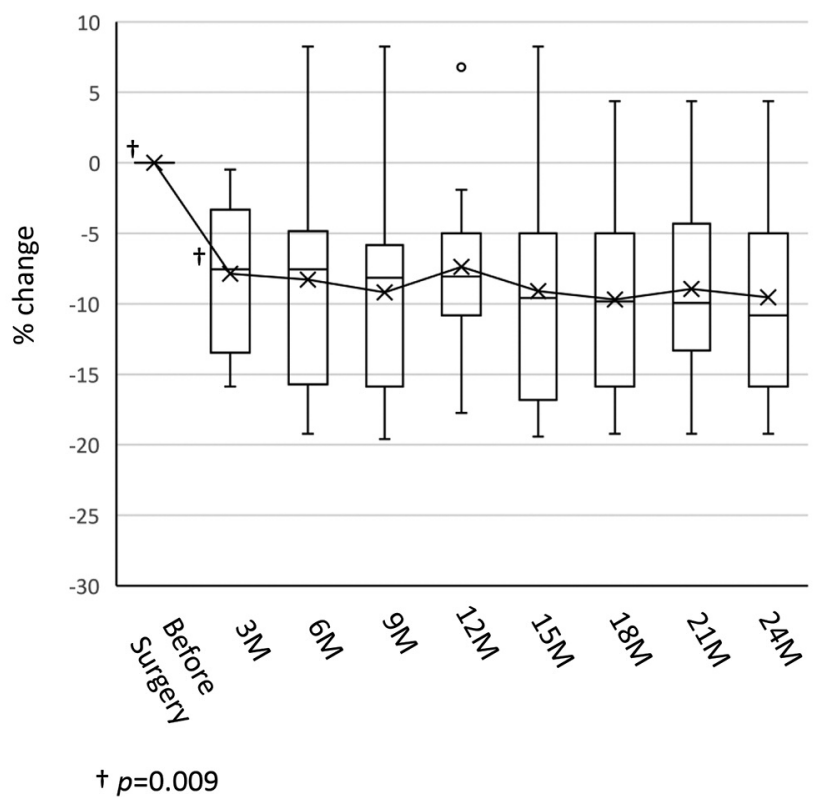

Figure 1. The percent changes from the baseline body weights in males (A) and females (B) are shown as boxplot. $\bigcirc$ : outlier; X: mean value. The line graph shows the change in the mean value.

higher in males than in females $[20.5 \mathrm{pg} / \mathrm{ml}$ (range=less than $10-43 \mathrm{pg} / \mathrm{ml}$ ) $v s$. less than $10 \mathrm{pg} / \mathrm{ml}$ (all less than $10 \mathrm{pg} / \mathrm{ml}$ ), $p<0.001]$. No recurrence was found during follow-up.

Changes in body weight. The body weights of male and female patients significantly decreased by $11.3 \%$ (range of change $=-24.64$ to $-2.86 \%, p<0.001$ ) and $7.6 \%$ (range of change $=-15.87$ to $-0.49, p=0.009)$, respectively, 3 months after surgery (Figure 1). There was no significant difference in the rate of change in body weight between male and female patients 3 months after surgery.

Changes in bone mineral density, vitamin D, and estradiol. DEXA showed that BMD 12 months after surgery decreased significantly by a median of $3.4 \%$ and $3.9 \%$ (range of change $=-8.1 \%$ to $2.5 \%, p=0.023$ ), in both male and female patients (range of change $=-14.3 \%$ to $2.4 \%, p<0.001$ ) respectively. There was no significant difference between male and female patients in the rate of change in BMD 12 months after surgery. Although BMD further decreased during the second postoperative year in both genders [males: median change $-1.6 \%$ (range of change $=-7.0 \%$ to $7.9 \%$ ), females: median value of $-0.8 \%$ (range of change $=-4.7$ to $3.9 \%)]$, the rates of change in BMD were less than in the first year (Figure 2). The number of patients with a $\mathrm{T}$ score of $\leq-1$ ("low bone mass" or osteoporosis) at 12 months was
27 of $47(57.5 \%)$. The serum 25(OH)VD level decreased 24 months after surgery by a median of $5 \mathrm{ng} / \mathrm{ml}$ (range of change $=-25$ to $5 \mathrm{ng} / \mathrm{ml}$ ) in male patients and by a median of $5 \mathrm{ng} / \mathrm{ml}$ (range of change $=-9$ to $7 \mathrm{ng} / \mathrm{ml}$ ) in female patients ( $p<0.001$ and $p=0.11$, respectively). There was no significant difference between male and female patients in the rate of change in the serum 25(OH)VD level 24 months after surgery (Figure 3). Meanwhile, the serum 1.25(OH) 2 VD levels after gastrectomy increased by a median of $13.4 \mathrm{pg} / \mathrm{ml}$ (range of change $=-2.0$ to $24.3 \mathrm{pg} / \mathrm{ml}$ ) 24 months after surgery in female patients, and by a median of $2.4 \mathrm{pg} / \mathrm{ml}$ (range of change $=-34.6$ to $37.3 \mathrm{pg} / \mathrm{ml}$ ) 24 months after surgery in male patients ( $p=0.016$ and $p=0.94$, respectively). There was a significant difference between female and male patients in the rate of change in serum $1,25(\mathrm{OH})_{2} \mathrm{VD}$ levels 24 months after surgery $(+13.35 \mathrm{pg} / \mathrm{ml} \mathrm{vs}$. $+2.4 \mathrm{pg} / \mathrm{ml}$, $p=0.028)$. However, both the serum 25(OH)VD and $1,25(\mathrm{OH})_{2} \mathrm{VD}$ levels remained within the nearly normal range throughout the observation period in both male and female patients (Figure 4). The serum E2 level in male patients significantly increased by a median value of 22 $\mathrm{pg} / \mathrm{ml}$ (range of change $=-14$ to $22 \mathrm{pg} / \mathrm{ml}$ ) 12 months after gastrectomy ( $p=0.030)$. Although not significantly, the serum E2 level in some female patients also increased after gastrectomy despite the fact that all of the female patients were menopausal (Figure 5). 
A

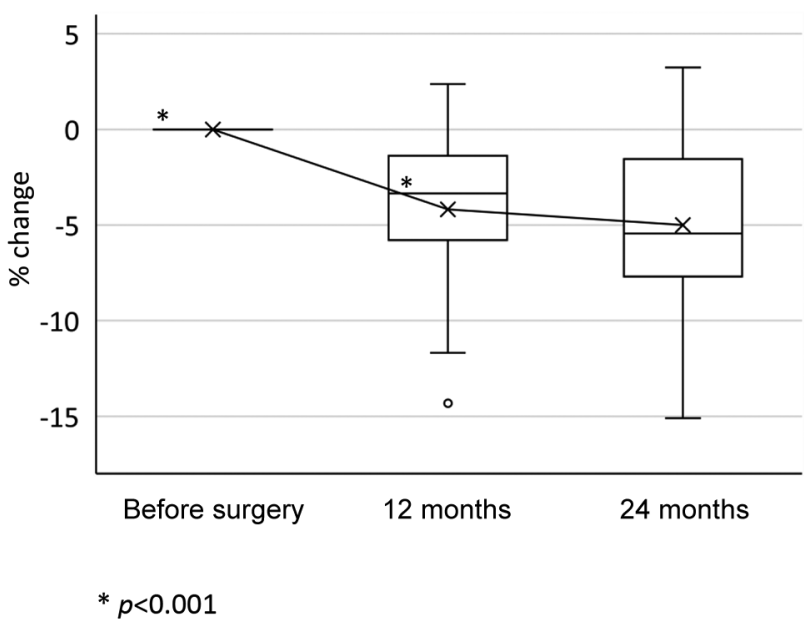

B

Females

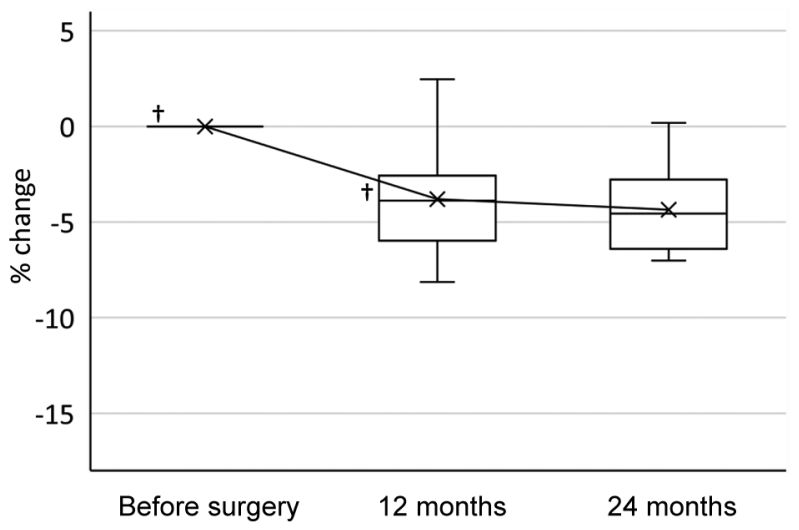

$+p=0.023$

Figure 2. The percent changes from the baseline body mineral density in males $(A)$ and females $(B)$ are shown as boxplot. $\bigcirc:$ outlier; X: mean value. The line graph shows the change in the mean value.

A

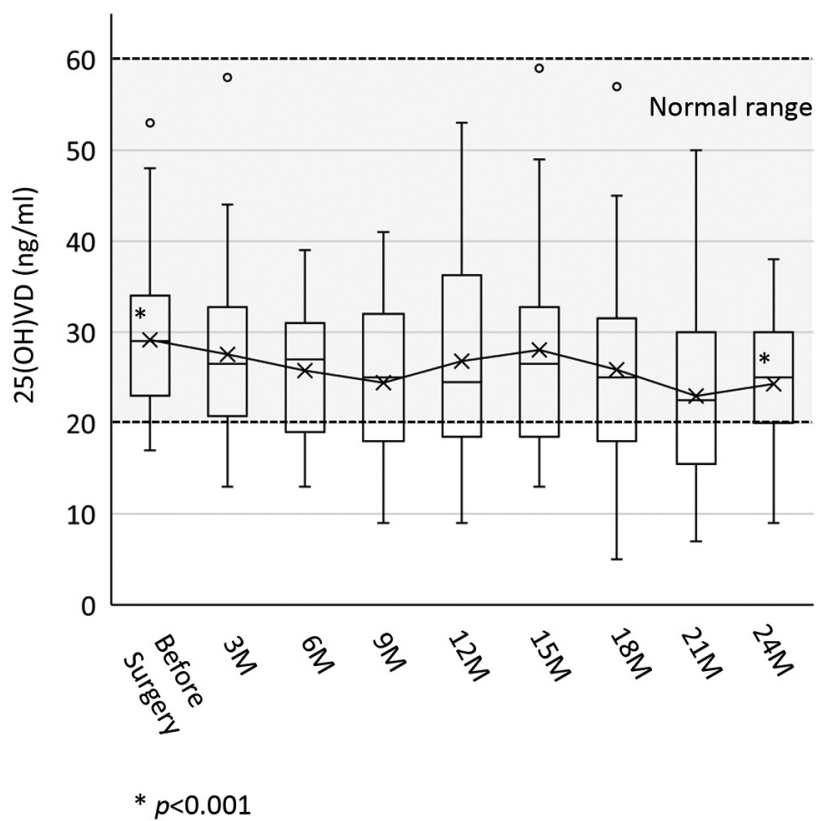

B

Females

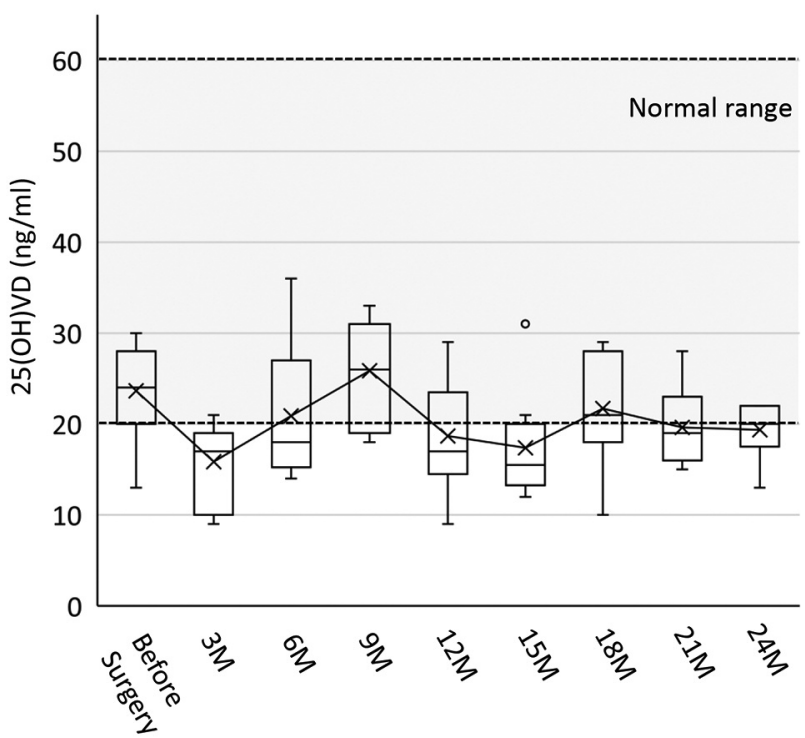

Figure 3. Serum 25-hydroxy vitamin D (25(OH)VD) levels in males $(A)$ and females $(B)$ before and after surgery are shown as boxplot. Shaded areas show the normal range of the serum $25(\mathrm{OH})$ VD level. $\bigcirc$ : outlier; X: mean value. The line graph shows the change in the mean value.

\section{Discussion}

In this study, we prospectively assessed the changes and gender-related differences in bone metabolism after gastric cancer surgery. Indeed, we demonstrated that BMD considerably decreased during the first postoperative year in both male and female patients with gastric cancer, and further decreased during the second postoperative year. There was no significant difference in the rate of change in BMD between male and female patients. Furthermore, both 
A

Males

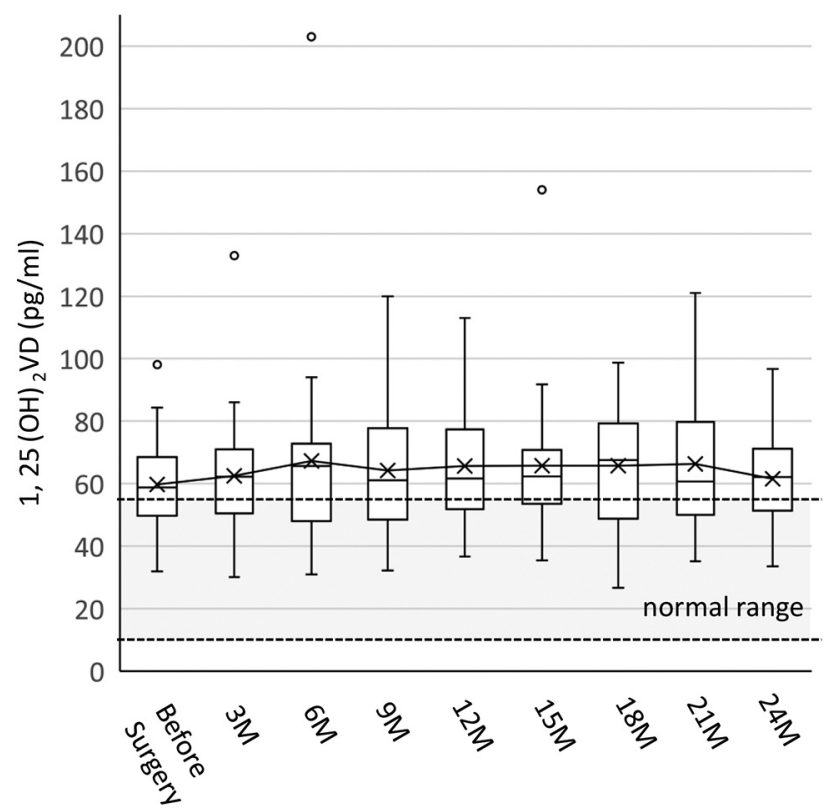

B

Females

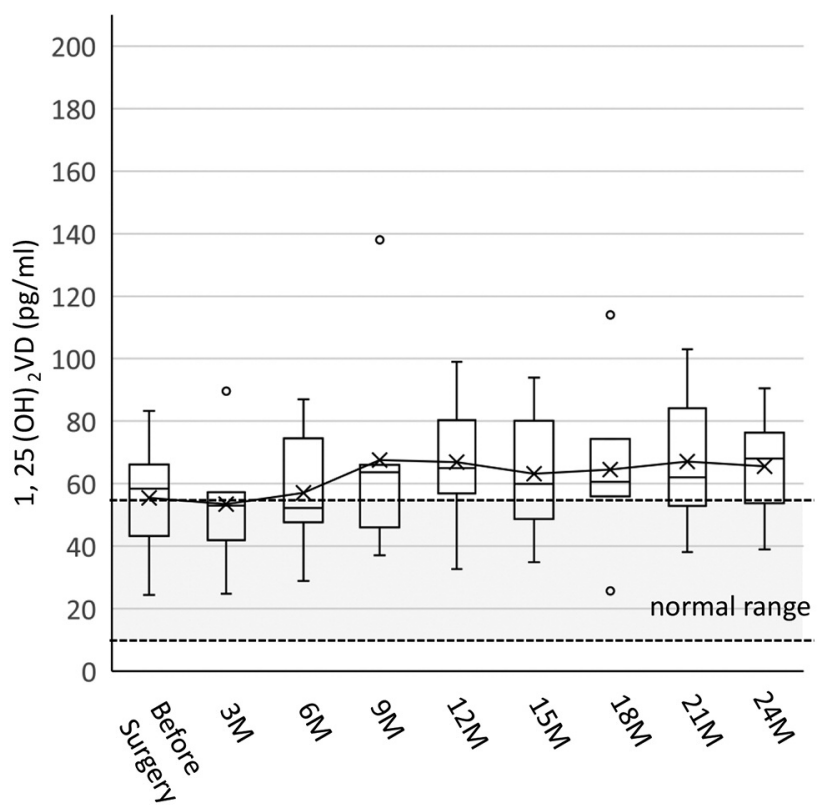

Figure 4. Serum 1,25-dihydroxy vitamin D (1,25(OH)2VD) levels in males $(A)$ and females $(B)$ before and after surgery. Shaded areas show the normal range of the serum 1,25-dihydroxy vitamin D (1,25(OH)2VD) level. $\bigcirc$ : outlier; X: mean value. The line graph shows the change in the mean value.

the serum $25(\mathrm{OH}) \mathrm{VD}$ and $1,25(\mathrm{OH}) 2 \mathrm{VD}$ levels remained within the nearly normal range for 2 years after surgery in both male and female patients in this study.

Previous cross-sectional studies showed that the BMD of the lumbar spine in normal adult males decreased gradually by about $5 \%$ in 10 years $(24,25)$. A previous large, longitudinal, multiethnic cohort study reported that the rate of spinal bone loss was about $2 \%$ per year in postmenopausal females (26), and a Japanese prospective study reported that the rate of spinal bone loss was $0.85 \%$ per year in Japanese postmenopausal females (27). As compared with these reports, bone loss in patients after gastrectomy in our study (3.4\% in males and $3.9 \%$ in females) was considerably higher, and gastrectomy appeared to be a stronger risk factor than menopause, especially in Japanese postmenopausal females. The only previous prospective study that included patients who had received adjuvant chemotherapy and had a follow-up period of only 12 months, showed a similar rate of BMD decrease $(-5.7 \%$ year) to that in our study (20). Thus, it was suggested that it is necessary to start BMD follow-up immediately after gastric cancer surgery in order to detect bone loss.

We demonstrated that the body weights of both male and female patients significantly decreased 3 months after surgery and remained nearly flat after that. It is interesting that this study also showed that BMD decreased during the first postoperative year and the rates of change in BMD during the second postoperative year were less than those during the first year, which were similar to the changes in the patients' body weights. We previously showed that reduced oral intake after gastrectomy gradually recovered and became stable from 6 months after surgery onward with a range from $82 \%$ to $91 \%$ of healthy individuals' food consumption (28). Other previous studies also showed that food intake decreased during the first postoperative year and improved subsequently $(29,30)$. This study and previous studies have suggested that reduced food consumption during the early postgastrectomy period might affect the BMD, and especially in females, the effect of the rapid decrease in food intake on BMD decline is greater than the effect of menopause.

Vitamin D, which is absorbed and produced in the small intestine and in the skin, is hydroxylated in the liver and kidney. The serum 25(OH) VD level reflects the body's store of vitamin $\mathrm{D}$, and $1,25(\mathrm{OH})_{2} \mathrm{VD}$ is the biologically active form of vitamin $\mathrm{D}$, which has important functions in calcium and bone metabolism. This study prospectively showed that the serum levels of both $25(\mathrm{OH}) \mathrm{VD}$ and $1,25(\mathrm{OH})_{2} \mathrm{VD}$ 
A

Males

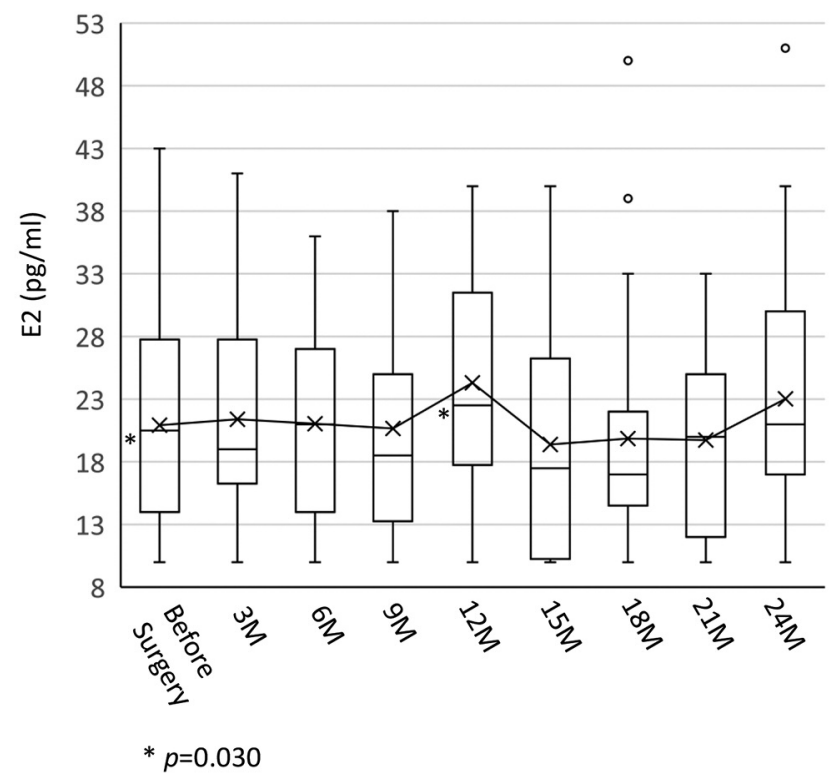

B

Females

Figure 5. Serum estradiol (E2) levels in males (A) and females (B) before and after surgery. $\bigcirc$ : outlier; X: mean value. The line graph shows the change in the mean value.

remained within the nearly normal range in both genders throughout the observation period. Pharmacologic treatment for bone disorders occurring after gastric cancer surgery has not been established. The results of this study suggest that only vitamin D supplementation might be insufficient and other drugs such as anti-bone resorbing agents might be needed to improve bone loss after gastric cancer surgery. Our previous study showed that alendronate administration significantly increased BMD in patients after gastrectomy whereas administration of only active vitamin D3 agent did not (31). A prospective study in patients with vitamin Dresistant osteopenia after gastrectomy showed that alendronate administration improved clinical symptoms and BMD of the lumbar spine (32). The results of the present study support these previous studies.

E2 is an estrogen steroid hormone and the major female sex hormone. E2 prevents bone loss by inhibiting osteoclast bone resorption and promoting osteoblast osteogenesis (33). Previous studies reported that estrogen was essential for the maintenance of bone mass not only in females but also in males (33-38). In previous studies, we showed that the serum E2 level increased after gastrectomy, especially in patients who had progressive bone disorders $(15,39)$. In the present study, male patients after gastrectomy showed a significantly elevated serum E2 level and some menopausal female patients also showed a slightly, but not significantly elevated serum E2 level. Our findings suggested that

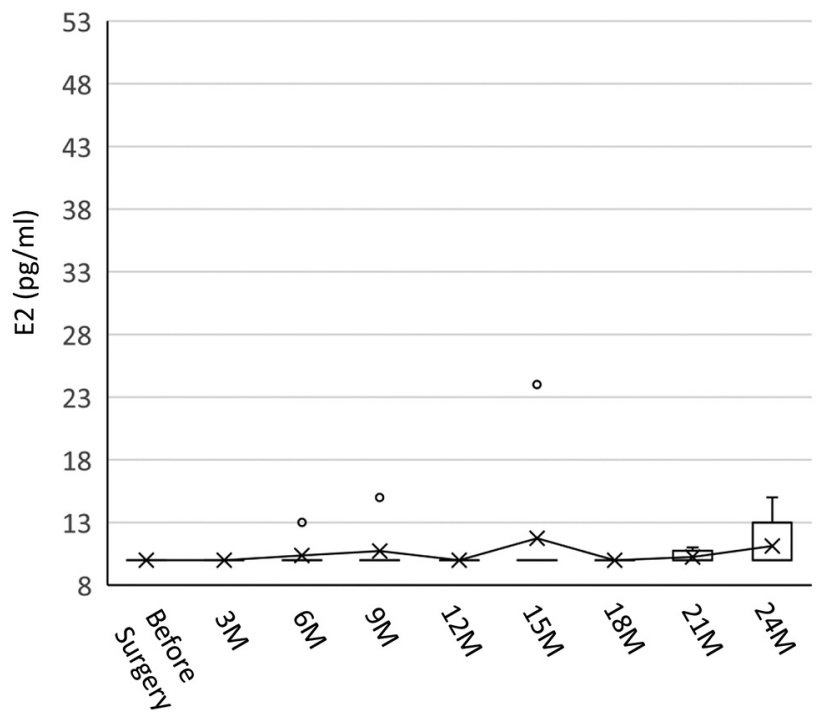

elevation of the serum E2 level might be a feedback reaction to inhibit bone loss.

Our study had several limitations. First, the sample size in this study was so small that we could not perform multivariate risk factor analysis to evaluate bone loss. A second limitation was that bone metabolic markers such as bone specific alkaline phosphatase (BAP), tartrate-resistant acid phosphatase (TRACP), type 1 collagen cross-linked Ntelopeptide (NTX), type 1 collagen C-terminal telopeptide (CTX), parathormone (PTH), and calcium were not measured. If they could be evaluated, pathological mechanisms and risk factors for bone loss after gastric cancer surgery might become clear. Third, our study was short-term and had a small number of subjects. Given these limitations, we suggest that it is important to investigate changes in BMD and bone metabolic markers after gastric cancer surgery and thereby, identify risk factors for bone loss in a large, long-term prospective study to establish a strategy for the prevention and treatment of bone metabolic disorders occurring after gastric cancer surgery.

\section{Conclusion}

This study showed that the BMD decreased significantly within 12 months after gastrectomy in both male and female patients with gastric cancer. There was no significant genderrelated difference in the rate of change in BMD. 


\section{Conflicts of Interest}

We are indebted to the following organizations for providing funding for this study: Daiichi Sankyo, Inc., Tsumura \& Co., Johnson and Johnson, Taiho Pharmaceutical Co., Ltd., Covidien Japan, Inc., Asahi Kasei Pharma Corporation, Kyowa Hakko Kirin Co. Ltd., and Yakult Honsha Co., Ltd.

\section{Authors' Contributions}

YA, YR, TA, KK, MN, HT, TO and NY conceived and coordinated the study, collected patient data, and participated in the statistical analysis; YA, YR, TA, NO, SK, and MM participated in preparing and drafting the manuscript; all Authors read and approved the final manuscript. YA and YR contributed equally to this article.

\section{Acknowledgements}

This study was funded by the Ministry of Education, Culture, Sports, Science and Technology of Japan, which provided Grantsin-aid for Scientific Research, the Japan Society for the Promotion of Science (19591553).

\section{References}

1 Sano T, Sasako M, Kinoshita T and Maruyama K: Recurrence of early gastric cancer. Follow-up of 1475 patients and review of the Japanese literature. Cancer 72(11): 3174-3178, 1993 PMID: 8242540. DOI: 10.1002/1097-0142(19931201)72:11 $<3174$ ::aid-cncr2820721107>3.0.co;2-h

2 Sakuramoto S, Sasako M, Yamaguchi T, Kinoshita T, Fujii M, Nashimoto A, Furukawa H, Nakajima T, Ohashi Y, Imamura H, Higashino M, Yamamura Y, Kurita A, Arai K and ACTS-GC Group: Adjuvant chemotherapy for gastric cancer with S-1, an oral fluoropyrimidine. N Engl J Med 357(18): 1810-1820, 2007. PMID: 17978289. DOI: 10.1056/NEJMoa072252

3 Rino Y, Yamamoto Y, Wada N, Yukawa N, Murakami H, Tamagawa H, Yamada T, Ohshima T, Masuda M and Imada T: Changes in vitamin D after gastrectomy. Gastric Cancer 10(4): 228-233, 2007. PMID: 18095078. DOI: 10.1007/s10120-0070439-2

4 Heaney RP: Health is better at serum 25(OH)D above $30 \mathrm{ng} / \mathrm{mL}$. J Steroid Biochem Mol Biol 136: 224-228, 2013. PMID: 23059471. DOI: 10.1016/j.jsbmb.2012.09.032

5 Rino Y: Clinical study of the relationship between a metabolic bone disorder and an amount of daily food intake. Yokohama Med J 47(1): 25-29, 1996.

6 Qu X, Huang X, Jin F, Wang H, Hao Y, Tang T and Dai K: Bone mineral density and all-cause, cardiovascular and stroke mortality: a meta-analysis of prospective cohort studies. Int J Cardiol 166(2): 385-393, 2013. PMID: 22112679. DOI: 10.1016/ j.ijcard.2011.10.114

7 Suzuki T and Yoshida H: Low bone mineral density at femoral neck is a predictor of increased mortality in elderly Japanese women. Osteoporos Int 21(1): 71-79, 2010. PMID: 19499274 DOI: 10.1007/s00198-009-0970-6

8 Oh HJ, Lim CH, Yoon BH, Yoon SB, Baeg MK, Kim WC, Cho YK, Park JM, Choi MG, Yoo HM, Song KY, Jeon HM and Park $\mathrm{CH}$ : Fracture after gastrectomy for gastric cancer: A long-term follow-up observational study. Eur J Cancer 72: 28-36, 2017. PMID: 28024264. DOI: 10.1016/j.ejca.2016.11.023

9 Sarasin C: Osteomalacie und hypochrome Anaemie nach Magenresektion. Digestion 66(3-4): 182-197, 2017. DOI: 10.1159/000198173

10 Inoue K, Shiomi K, Higashide S, Kan N, Nio Y, Tobe T, Shigeno $\mathrm{C}$, Konishi J, Okumura $\mathrm{H}$ and Yamamuro T: Metabolic bone disease following gastrectomy: assessment by dual energy X-ray absorptiometry. Br J Surg 79(4): 321-324, 1992. PMID: 1576498. DOI: $10.1002 /$ bjs. 1800790413

11 Kobayashi S, Takahashi C, Kuroda T, Sugenoya A, Iida F and Katoh K: Calcium regulating hormones and bone mineral content in patients after subtotal gastrectomy. Surg Today 24(4): 295-298, 1994. PMID: 8038501. DOI: 10.1007/BF02348555

12 Liedman B, Bosaeus I, Mellström D and Lundell L: Osteoporosis after total gastrectomy. Results of a prospective, clinical study. Scand J Gastroenterol 32(11): 1090-1095, 1997. PMID: 9399388. DOI: 10.3109/00365529709002986

13 Mellström D, Johansson C, Johnell O, Lindstedt G, Lundberg PA, Obrant K, Schöön IM, Toss G and Ytterberg BO: Osteoporosis, metabolic aberrations, and increased risk for vertebral fractures after partial gastrectomy. Calcif Tissue Int 53(6): 370-377, 1993. PMID: 8293349.

14 Nishimura O, Furumoto T, Nosaka K, Kouno K, Sumikawa M, Hisaki T, Odachi T, Mizumoto K, Kishimoto H and Yamamoto $\mathrm{K}$ : Bone disorder following partial and total gastrectomy with reference to bone mineral content. Jpn J Surg 16(2): 98-105, 1986. PMID: 3723890 . DOI: 10.1007/BF02471078

15 Rino Y, Takanashi Y, Yamamoto Y, Inagaki D, Kawamoto M, Harada H, Ashida A, Wada H, Yamada R, Ohshima T, Hatori S and Imada T: Bone disorder and vitamin D after gastric cancer surgery. Hepatogastroenterology 54(77): 1596-1600, 2007. PMID: 17708309.

16 Atsumi Y, Rino Y, Wada H, Kitani Y, Ozawa Y, Aoyama T, Oshima T, Yukawa N, Yoshikawa T and Masuda M: Changes in bone metabolism after gastric cancer surgery in male patients: a prospective observational study. Gastric Cancer 22(1): 237-243, 2019. PMID: 29748875. DOI: 10.1007/s10120-018-0835-9

17 Bang YJ, Kim YW, Yang HK, Chung HC, Park YK, Lee KH, Lee KW, Kim YH, Noh SI, Cho JY, Mok YJ, Kim YH, Ji J, Yeh TS, Button P, Sirzén F, Noh SH and CLASSIC trial investigators: Adjuvant capecitabine and oxaliplatin for gastric cancer after D2 gastrectomy (CLASSIC): a phase 3 open-label, randomised controlled trial. Lancet 379(9813): 315-321, 2012. PMID: 22226517. DOI: 10.1016/S0140-6736(11)61873-4

18 Fuse N, Bando H, Chin K, Ito S, Yoshikawa T, Tsuburaya A, Terashima M, Kawashima Y, Fukunaga T, Gotoh M, Emi Y, Yoshida K, Oki E, Takahashi S, Kuriki H, Sato K and Sasako M: Adjuvant capecitabine plus oxaliplatin after D2 gastrectomy in Japanese patients with gastric cancer: a phase II study. Gastric Cancer 20(2): 332-340, 2017. PMID: 26956689. DOI: 10.1007/ s10120-016-0606-4

19 Nakamura M, Ishiguro A, Muranaka T, Fukushima H, Yuki S, Ono K, Murai T, Matsuda C, Oba A, Itaya K, Sone T, Yagisawa M, Koike Y, Endo A, Tsukuda Y, Ono Y, Kudo T, Nagasaka A, Nishikawa S and Komatsu Y: A prospective observational study on effect of short-term periodic steroid premedication on bone metabolism in gastrointestinal cancer (ESPRESSO-01). Oncologist 22(5): 592-600, 2017. PMID: 28341762. DOI: 10.1634/theoncologist.2016-0308 
20 Baek KH, Jeon HM, Lee SS, Lim DJ, Oh KW, Lee WY, Rhee EJ, Han JH, Cha BY, Lee KW, Son HY, Kang SK and Kang MI: Short-term changes in bone and mineral metabolism following gastrectomy in gastric cancer patients. Bone 42(1): 61-67, 2008. PMID: 17942383. DOI: 10.1016/j.bone.2007.08.027

21 Kanis JA, Melton LJ 3rd, Christiansen C, Johnston CC and Khaltaev N: The diagnosis of osteoporosis. J Bone Miner Res 9(8): 1137-1141, 1994. PMID: 7976495. DOI: 10.1002/jbmr. 5650090802

22 Cosman F, de Beur SJ, LeBoff MS, Lewiecki EM, Tanner B, Randall S, Lindsay R and National Osteoporosis Foundation: Clinician's guide to prevention and treatment of osteoporosis. Osteoporos Int 25(10): 2359-2381, 2014. PMID: 25182228. DOI: $10.1007 / \mathrm{s} 00198-014-2794-2$

23 Kanda Y: Investigation of the freely available easy-to-use software 'EZR' for medical statistics. Bone Marrow Transplant 48(3): 452-458, 2013. PMID: 23208313. DOI: 10.1038/bmt. 2012.244

24 Riggs BL, Wahner HW, Dunn WL, Mazess RB, Offord KP and Melton LJ 3rd: Differential changes in bone mineral density of the appendicular and axial skeleton with aging: relationship to spinal osteoporosis. J Clin Invest 67(2): 328-335, 1981. PMID: 7462421. DOI: 10.1172/JCI110039

25 Kin K, Kushida K, Yamazaki K, Okamoto S and Inoue T: Bone mineral density of the spine in normal Japanese subjects using dual-energy X-ray absorptiometry: effect of obesity and menopausal status. Calcif Tissue Int 49(2): 101-106, 1991. PMID: 1913287. DOI: 10.1007/BF02565129

26 Finkelstein JS, Brockwell SE, Mehta V, Greendale GA, Sowers MR, Ettinger B, Lo JC, Johnston JM, Cauley JA, Danielson ME and Neer RM: Bone mineral density changes during the menopause transition in a multiethnic cohort of women. J Clin Endocrinol Metab 93(3): 861-868, 2008. PMID: 18160467. DOI: $10.1210 /$ jc. $2007-1876$

27 Iki M, Kajita E, Dohi Y, Nishino H, Kusaka Y, Tsuchida C, Yamamoto $\mathrm{K}$ and Ishii $\mathrm{Y}$ : Age, menopause, bone turnover markers and lumbar bone loss in healthy Japanese women. Maturitas 25(1): 59-67, 1996. PMID: 8887310. DOI: 10.1016/ 0378-5122(96)01042-0

28 Saeki H, Rino Y, Cho H, Sato T, Kawamoto M, Takanashi Y, Yamada R, Oshima T, Hatori S and Imada T: Evaluation of calorie intake according to age and sex in patients undergoing surgery for gastric cancer. Hepatogastroenterology 55(82-83): 795-798, 2008. PMID: 18613457.

29 Karanicolas PJ, Graham D, Gönen M, Strong VE, Brennan MF and Coit DG: Quality of life after gastrectomy for adenocarcinoma: a prospective cohort study. Ann Surg 257(6): 1039-1046, 2013. PMID: 23665970. DOI: 10.1097/SLA. 0b013e31828c4a19

$30 \mathrm{Yu}$ W, Park KB, Chung HY, Kwon OK and Lee SS: Chronological changes of quality of life in long-term survivors after gastrectomy for gastric cancer. Cancer Res Treat 48(3): 1030-1036, 2016. PMID: 27004956. DOI: 10.4143/crt.2015.398
31 Atsumi Y, Rino Y, Sato T, Cho H, Yoshikawa T, Yamamoto N, Oshima T, Yukawa N, Shiozawa M, Morinaga S and Masuda M: Effectiveness of alendronate for bone disorder after gastrectomy for gastric cancer. Asian J Surg 40(6): 470-474, 2017. PMID: 27546020. DOI: 10.1016/j.asjsur.2016.07.003

32 Suzuki Y, Ishibashi Y, Omura N, Kawasaki N, Kashiwagi H, Yanaga $\mathrm{K}$, Abo $\mathrm{M}$ and Urashima $\mathrm{M}$ : Alendronate improves vitamin D-resistant osteopenia triggered by gastrectomy in patients with gastric cancer followed long term. J Gastrointest Surg 9(7): 955-960, 2005. PMID: 16137591. DOI: 10.1016/ j.gassur.2005.04.020

33 Riggs BL, Khosla S and Melton LJ 3rd: A unitary model for involutional osteoporosis: estrogen deficiency causes both type I and type II osteoporosis in postmenopausal women and contributes to bone loss in aging men. J Bone Miner Res 13(5): 763-773, 1998. PMID: 9610739. DOI: 10.1359/jbmr. 1998.13.5.763

34 Slemenda CW, Longcope C, Zhou L, Hui SL, Peacock M and Johnston CC: Sex steroids and bone mass in older men. Positive associations with serum estrogens and negative associations with androgens. J Clin Invest 100(7): 1755-1759, 1997. PMID: 9312174. DOI: 10.1172/JCI119701

35 Greendale GA, Edelstein S and Barrett-Connor E: Endogenous sex steroids and bone mineral density in older women and men: the Rancho Bernardo Study. J Bone Miner Res 12(11): 18331843, 1997. PMID: 9383688. DOI: 10.1359/jbmr.1997. 12.11 .1833

36 Khosla S, Melton LJ 3rd, Atkinson EJ, O'Fallon WM, Klee GG and Riggs BL: Relationship of serum sex steroid levels and bone turnover markers with bone mineral density in men and women: a key role for bioavailable estrogen. J Clin Endocrinol Metab 83(7): 2266-2274, 1998. PMID: 9661593. DOI: 10.1210/jcem. 83.7.4924

37 Bernecker P, Willvonseder R and Resch H: Decreased estrogenlevels in male-patients with primary osteoporosis. Blackwell Science Publ Inc., Cambridge, MA, USA, 1995.

38 Center J, Nguyen T, White C and Eisman J: Male osteoporosis predictors: Sex hormones and calcitropic hormones: Blackwell Science Inc., Malden, MA, USA, 1997.

39 Rino Y, Yukawa N, Yamamoto N, Ohshima T, Sato T, Tamagawa H, Suganuma N, Hasegawa S, Fujikawa Y, Nakazono M, Yoshikawa T, Masuda M and Imada T: Self-defensive response to bone disorder after gastric cancer surgery. Clinical and Experimental Medical Sciences 2: 1-10, 2016. DOI: 10.12988/ cems.2014.397 